\title{
Rationally Designed Antibodies as Research Tools to Study the Structure-Toxicity Relationship of Amyloid- $\beta$ Oligomers
}

\author{
Ryan Limbocker ${ }^{1,2, *}$, Benedetta Mannini ${ }^{1}{ }^{\mathbb{D}}$, Rodrigo Cataldi ${ }^{1}\left(\mathbb{D}\right.$, Shianne Chhangur ${ }^{1}$, \\ Aidan K. Wright ${ }^{2}$, Ryan P. Kreiser ${ }^{2}$, J. Alex Albright ${ }^{2}$, Sean Chia ${ }^{1}$, Johnny Habchi ${ }^{1}$, \\ Pietro Sormanni ${ }^{1}$, Janet R. Kumita ${ }^{1}\left(\mathbb{D}\right.$, Francesco S. Ruggeri ${ }^{1}{ }^{(D}$, Christopher M. Dobson ${ }^{1, \ddagger}$, \\ Fabrizio Chiti ${ }^{3}$, Francesco A. Aprile ${ }^{1, *,+}$ and Michele Vendruscolo ${ }^{1, *(D)}$ \\ 1 Centre for Misfolding Diseases, Department of Chemistry, University of Cambridge, Cambridge CB2 1EW, \\ UK; bm475@cam.ac.uk (B.M.); rlc67@cam.ac.uk (R.C.); sc2066@cam.ac.uk (S.C.); skrc2@cam.ac.uk (S.C.); \\ jh884@cam.ac.uk (J.H.); ps589@cam.ac.uk (P.S.); jrk38@cam.ac.uk (J.R.K.); fsr26@cam.ac.uk (F.S.R.) \\ 2 Department of Chemistry and Life Science, United States Military Academy, West Point, NY 10996, USA; \\ aidan.wright@westpoint.edu (A.K.W.); ryan.kreiser@westpoint.edu (R.P.K.); \\ james.albright@westpoint.edu (J.A.A.) \\ 3 Department of Experimental and Clinical Biomedical Science, University of Florence, 50134 Florence, Italy; \\ fabrizio.chiti@unifi.it \\ * Correspondence: ryan.limbocker@westpoint.edu (R.L.); f.aprile@imperial.ac.uk (F.A.A.); \\ mv245@cam.ac.uk (M.V.) \\ + Present address: Department of Chemistry, Molecular Science Research Hub, Imperial College London, \\ London W12 0BZ, UK. \\ $\ddagger$ This author had passed away.
}

Received: 27 May 2020; Accepted: 15 June 2020; Published: 25 June 2020

Abstract: Alzheimer's disease is associated with the aggregation of the amyloid- $\beta$ peptide $(A \beta)$, resulting in the deposition of amyloid plaques in brain tissue. Recent scrutiny of the mechanisms by which $A \beta$ aggregates induce neuronal dysfunction has highlighted the importance of the $A \beta$ oligomers of this protein fragment. Because of the transient and heterogeneous nature of these oligomers, however, it has been challenging to investigate the detailed mechanisms by which these species exert cytotoxicity. To address this problem, we demonstrate here the use of rationally designed single-domain antibodies (DesAbs) to characterize the structure-toxicity relationship of $A \beta$ oligomers. For this purpose, we use $\mathrm{Zn}^{2+}$-stabilized oligomers of the 40-residue form of $\mathrm{A} \beta\left(\mathrm{A} \beta_{40}\right)$ as models of brain $A \beta$ oligomers and two single-domain antibodies (Des $A b_{18-24}$ and DesA $b_{34-40}$ ), designed to bind to epitopes at residues 18-24 and 34-40 of $A \beta_{40}$, respectively. We found that the DesAbs induce a change in structure of the $\mathrm{Zn}^{2+}$-stabilized $\mathrm{A} \beta_{40}$ oligomers, generating a simultaneous increase in their size and solvent-exposed hydrophobicity. We then observed that these increments in both the size and hydrophobicity of the oligomers neutralize each other in terms of their effects on cytotoxicity, as predicted by a recently proposed general structure-toxicity relationship, and observed experimentally. These results illustrate the use of the DesAbs as research tools to investigate the biophysical and cytotoxicity properties of $A \beta$ oligomers.

Keywords: protein misfolded oligomers; structure-toxicity relationship; rationally designed antibodies; research tools; biophysics; amyloid- $\beta$; Alzheimer's disease

\section{Introduction}

The development and progression of Alzheimer's disease (AD) is characterized by the misfolding and aggregation of the amyloid- $\beta$ peptide $(A \beta)$, which eventually results in the formation of dense 
senile plaques rich in fibrillar $A \beta$ aggregates [1-3]. Increasing evidence suggests that the oligomeric aggregates which form as intermediates during the $\mathrm{A} \beta$ deposition process, rather than mature fibrils, are the predominant species capable of inducing neuronal dysfunction [4-7]. Targeting the rates of formation or the physicochemical properties of $A \beta$ oligomers, therefore, represents one of the most promising therapeutic approaches to the treatment of $\mathrm{AD}[8,9]$.

Intense focus on inhibiting $A \beta$ deposition has resulted in the characterization of numerous molecules, including small molecules, antibodies and molecular chaperones, which are able to prevent $A \beta$ aggregation, and therefore, reduce the rate of $A \beta$ oligomer formation, although no disease-modifying compound has yet been approved for clinical use $[10,11]$. These failures are, in part, attributable to the inclusion in clinical trials of participants without $\mathrm{A} \beta$-related pathologies, thus confounding the analysis, and of participants with advanced $\mathrm{AD}$, when the amyloid burden has already reached an advanced stage, making potential drugs against $A \beta$-induced neuronal damage less effective [12-14]. They are also a consequence of poor quantitative endpoints regarding the impact of candidate inhibitors on the microscopic steps governing $A \beta$ aggregation, including the number of the highly cytotoxic oligomeric species produced in the presence of potential therapeutics [15-21], as well as an incomplete mechanistic understanding of the impact of candidate compounds on the physicochemical properties of oligomeric species and their closely related ability to induce cytotoxicity.

Given the advantages of using antibodies as research tools [22,23], in particular for their very high selectivity for a specific target (e.g., epitopes on the surface of $A \beta$ oligomers) $[18,24,25]$, in addition to reports that have illustrated the efficacy of anti-A $\beta$ immunotherapies $[9,26]$ and the potential of anti-A $\beta$ antibodies for early diagnosis $[27,28]$, we recently focused on the development of rationally designed antibodies to inhibit the aggregation of $A \beta$ through the selective targeting of specific microscopic steps inherent to its self-assembly and propagation [18]. Of particular note, we previously found that the designed single-domain antibody raised against residues $18-24$ of $A \beta\left(\operatorname{Des}_{18-24}\right)$ is a potent inhibitor of the microscopic step of primary nucleation of the $A \beta_{42}$ amyloid fibril formation process. Moreover, its administration to a $C$. elegans model of $A D$ was shown to reduce the toxicity implicit to $A \beta_{42}$ aggregation when administered before or during the development of a pathological phenotype [18]. In light of these observations, and to contribute new tools with which to study the impact of candidate therapeutic compounds on the physicochemical properties of intermediate oligomeric species, we sought to assess the impact of this and a second rationally designed single-domain antibody raised against residues 34-40 of $A \beta_{40}$ (DesA $b_{34-40}$ ) on stabilized cytotoxic oligomeric species of $A \beta_{40}$ after their formation, which were generated from both primary and secondary nucleation pathways in the endogenous $A \beta$ aggregation reaction [19].

To investigate the relationship between the structure and the toxicity of $A \beta_{40}$ oligomers, we first determined the effects of DesAb $b_{18-24}$ and DesAb $b_{34-40}$ on the in vitro aggregation of $A \beta_{40}$. Then, we analyzed the effects of these DesAbs on the size and hydrophobicity of $\mathrm{Zn}^{2+}$-stabilized $\mathrm{A} \beta_{40}$ oligomers formed under near physiological conditions. We found that the DesAbs induced the formation of larger and more hydrophobic $A \beta_{40}$ oligomers. As a control, we then showed that the natural product trodusquemine, which protects cell membranes from the cytotoxic effects of protein misfolded oligomers at substoichiometric concentrations [29], induces similar effects to these DesAbs when used at concentrations that are superstoichiometric and higher than those normally used in cells or patients due to its intrinsic toxicity. Increases in size and hydrophobicity are known to cause a decrease and increase of oligomer toxicity, respectively [30-36]. In fact, consistent with previous quantifications of the size-hydrophobicity relationship modulated by mutations on another protein system [30], we observed that these effects mediated by our DesAbs on $A \beta_{40}$ did not significantly change the degree of cytotoxicity of the oligomers towards SH-SY5Y neuroblastoma cells, indicating that the simultaneous increase in oligomer size and hydrophobicity produces antagonistic effects on oligomer toxicity. 


\section{Results}

\subsection{The DesAbs Inhibit $A \beta_{40}$ Aggregation}

In this work, we investigate two computationally-designed, single-domain antibodies, called DesAb $\mathrm{Ab}_{18-24}$ and DesAb $\mathrm{B}_{34-40}$, which target the regions 18-24 and 34-40 of $\mathrm{A} \beta_{40}$, respectively. These antibodies were generated by grafting a complementary peptide into the third complementary determining region (CDR3) of a single-domain antibody scaffold, as described previously [18,37].

We first investigated the effect of these two DesAbs on $A \beta_{40}$ aggregation. Samples containing monomeric $\mathrm{A} \beta_{40}$ at a concentration of $10 \mu \mathrm{M}(20 \mathrm{mM}$ Tris, $100 \mathrm{mM} \mathrm{NaCl}, \mathrm{pH} 7.4)$ were prepared in the absence and presence of 20-, 10-, and 5-fold substoichiometric concentrations of the designed antibodies and incubated under quiescent conditions at $37^{\circ} \mathrm{C}$. The fibrilization process was monitored by means of thioflavin T fluorescence (ThT) in the presence of $20 \mu \mathrm{M}$ ThT. We observed that DesAb $18-24$ strongly inhibits $A \beta_{40}$ aggregation, causing a significant delay in the half-time of aggregation $\left(t_{1 / 2}\right)$ (Figure $\left.1 \mathrm{a}\right)$, which is in agreement with previous findings for $A \beta_{42}$ [18]. Indeed, at the highest concentration of Des $A b_{18-24}(2 \mu \mathrm{M}), A \beta_{40}$ did not aggregate beyond $t_{1 / 2}$ in this experiment on the time course of $25 \mathrm{~h}$. Further experiments on DesAb $\mathrm{b}_{34-40}$ revealed that this designed antibody was also able to interfere with the reaction, as observed by an overall delay in the aggregation kinetics (Figure 1b). Interestingly, both DesAbs inhibited the aggregation kinetics in a concentration-dependent manner, as illustrated by the relative changes in $t_{1 / 2}$ (Figure $1 c$ ). Experiments were carried out in triplicate, and indicated that both designed antibodies can significantly delay $\mathrm{A} \beta_{40}$ aggregation.

a

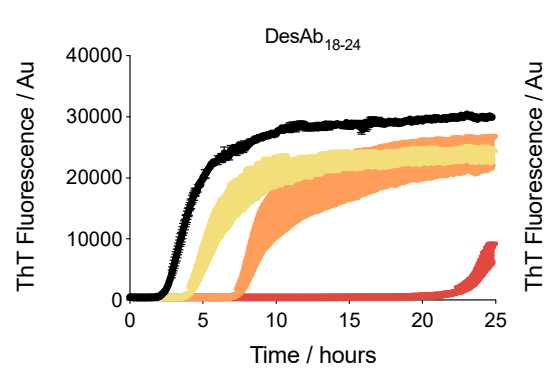

b

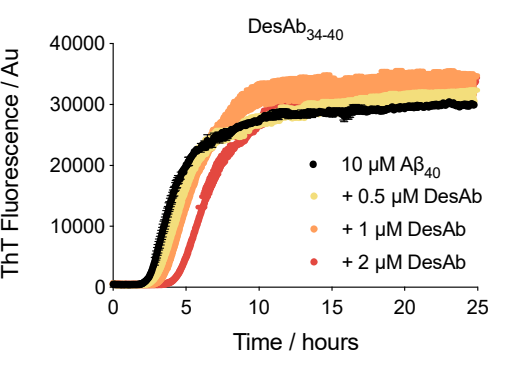

C

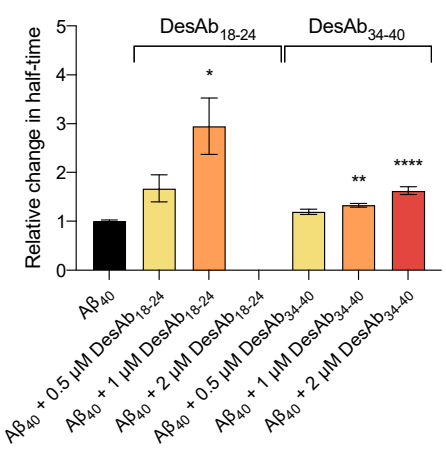

Figure 1. Des $A b_{18-24}$ and DesAb $b_{34-40}$ inhibit $A \beta_{40}$ aggregation. (a,b) Thioflavin $T(T h T)$ fluorescence intensity profiles for the aggregation of $A \beta_{40}(10 \mu \mathrm{M})$ incubated in the absence (black) and presence of $0.5 \mu \mathrm{M}$ (yellow), $1 \mu \mathrm{M}$ (orange) and $2 \mu \mathrm{M}$ (red) DesAb $\mathrm{A}_{18-24}$ (a) and DesAb $\mathrm{b}_{34-40}$ (b). Upward error bars indicate standard error of the mean (SEM) of three technical replicates. (c) Relative change in half-time $\left(t_{1 / 2}\right)$ calculated from dividing $t_{1 / 2}$ for each experimental condition by the average $t_{1 / 2}$ determined for $\mathrm{A} \beta_{40}$ in the absence of DesAbs to show the relative delay in aggregation induced by the antibodies. Error bars indicate SEM of three technical replicates. Individual antibody groups were analyzed by one-way ANOVA followed by a Bonferroni's multiple comparison test relative to $\mathrm{A} \beta_{40}$ in buffer. The symbols ${ }^{*} * *$, and ${ }^{* * *}$ indicate $p<0.05,0.01$ and 0.0001 , respectively.

\subsection{The DesAbs Bind Stabilized $A \beta_{40}$ Oligomers and Increase Their Hydrophobic Surface Area}

During the aggregation of $A \beta_{40}$ at the concentrations used here, the peak oligomer concentration reached circa $1 \%$ of the total monomer concentration at the half-point of the aggregation reaction $[21,38]$. Given the very low abundance and high instability of on-pathway oligomers, numerous methods have been described to generate and stabilize oligomers at concentrations that are orders of magnitude higher [39-42]. For this purpose, oligomers of $\mathrm{A} \beta_{40}$ stabilized by $\mathrm{Zn}^{2+}$ were produced as previously described [42]. These oligomers are stabilized by a metal ion that is naturally present at the synapse, and may therefore resemble those that exist in AD [42]. 
We first tested the ability of these antibodies to bind to stabilized $A \beta_{40}$ oligomers using a dot-blot assay (Supplementary Figure S1). Then, we evaluated the degree of hydrophobicity of the oligomers in the absence and presence of the DesAbs using the fluorescent dye 8-anilinonapthalene-1-sulfonic acid (ANS), which binds to hydrophobic patches on the surfaces of protein aggregates, generating a quantum yield increase and blue shift of fluorescence relative to unbound dye [43]. We incubated stabilized $\mathrm{A} \beta_{40}$ oligomers after their formation [42] for $2 \mathrm{~h}$ at $20^{\circ} \mathrm{C}$ at a concentration of $10 \mu \mathrm{M}$ (in monomer equivalents) in $20 \mathrm{mM}$ Tris, $100 \mathrm{mM} \mathrm{NaCl}$ and at $\mathrm{pH} 7.4$ in the absence and presence of increasing concentrations $(0.2 \mu \mathrm{M}, 0.5 \mu \mathrm{M}, 1 \mu \mathrm{M}$, and $2 \mu \mathrm{M})$ of each antibody. After incubation, ANS was added to a final concentration of $30 \mu \mathrm{M}$ (i.e., 3-fold excess). Similar to our previous characterization for $\mathrm{A} \beta_{42}$ oligomers [29], ANS fluorescence intensity was observed to increase and undergo a blue-shift from ca. $510 \mathrm{~nm}$ to ca. $475 \mathrm{~nm}$ in the presence of stabilized $A \beta_{40}$ oligomers. Incubation in the presence of increasing concentrations of DesAb $\mathrm{b}_{18-24}$ and DesAb $\mathrm{b}_{34-40}$ resulted in the amplification of this effect with a clear, well-defined dose dependence (Figure 2a,b). Data were quantified by maximum ANS fluorescence intensity (Figure 2c,d). Representative data are shown for three independent protein preparations that yielded consistent results. The incubation of $2 \mu \mathrm{M}$ DesAbs (i.e., the highest ratio tested) in the absence of oligomers exerted a negligible effect on ANS fluorescence. These results indicate that the hydrophobicity of the $A \beta_{40}$ oligomers increased as a function of antibody concentration.
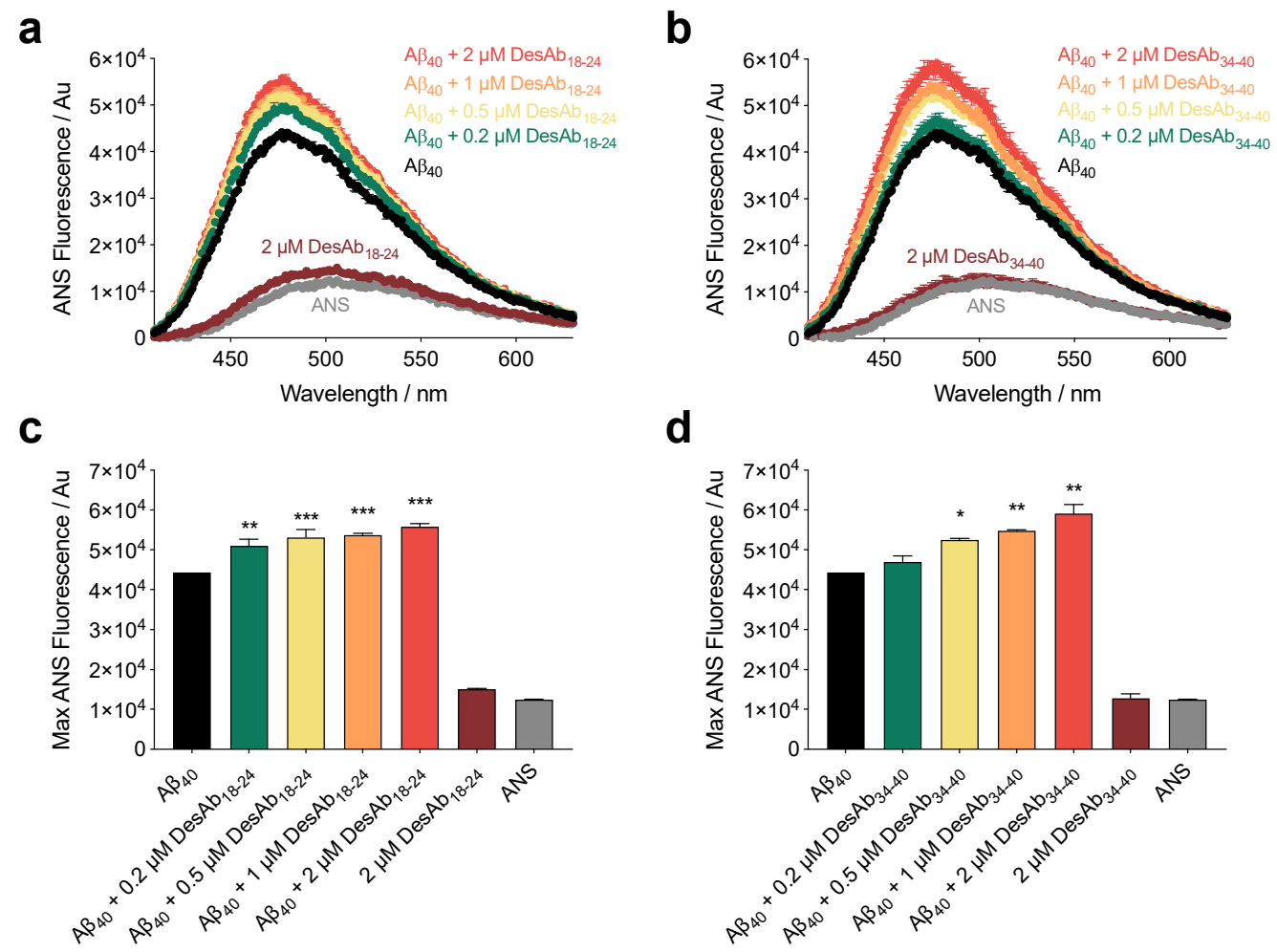

Figure 2. DesAb $b_{18-24}$ and DesAb $b_{34-40}$ increase the hydrophobic area of stabilized $A \beta_{40}$ oligomers. ANS binding measurements for oligomers of $A \beta_{40}$ incubated at a concentration of $10 \mu \mathrm{M}$ in the absence (black) or presence of $0.2 \mu \mathrm{M}$ (green), $0.5 \mu \mathrm{M}$ (yellow), $1 \mu \mathrm{M}$ (orange) and $2 \mu \mathrm{M}$ (red) DesAb $18-24$ (a) and $\operatorname{DesAb}_{34-40}(\mathbf{b})$. The intensity of maximum ANS fluorescence for DesAb $\mathrm{b}_{18-24}$ (c) and $\operatorname{DesAb}_{34-40}(\mathbf{d})$, determined from the spectra indicated in (a) and (b), respectively. Note that the highest concentration of DesAbs tested ( $2 \mu \mathrm{M}$, dark red) did not significantly change the fluorescence of free ANS (grey) in the absence of oligomers. Error bars denote SEM of duplicate spectra. Samples containing oligomers were analyzed by one-way ANOVA followed by a Bonferroni's multiple comparison test relative to oligomers in buffer. The symbols ${ }^{*}{ }^{* *}$, and ${ }^{* * *}$ indicate $p<0.05,0.01$ and 0.001 , respectively. 


\subsection{DesAbs Increase the Size of Stabilized $A \beta_{40}$ Oligomers}

We hypothesized that DesAb $\mathrm{b}_{18-24}$ and DesAb $\mathrm{b}_{34-40}$ may be able to sequester the aggregates in solution via a clustering-based mechanism. This mechanism has been described for molecular chaperones in the presence of several oligomeric species comprising various peptides and proteins $[31-33,35]$. To probe this interaction, we first measured the turbidimetry absorbance (turbidity) of the same samples that were investigated in the ANS experiment. In parallel with an increase in hydrophobicity, we also observed that the spectra were shifted to higher values of turbidity as a function of antibody concentration (Figure 3a,b). Data were quantified by integrating the area under each curve (Figure $3 c, d$ ). The results shown are representative of three independent experiments that gave consistent results. It should be noted that the highest concentration of DesAbs used in our experiments absorbed at a level which cannot recapitulate the full effects observed on size in the presence of the oligomers, indicating that the antibody exerts a negligible effect on absorbance in the absence of oligomers. These results demonstrate that the size of the oligomers increased in a dose-dependent manner by $\operatorname{DesAb}_{18-24}$ and DesAb $34-40$.

a

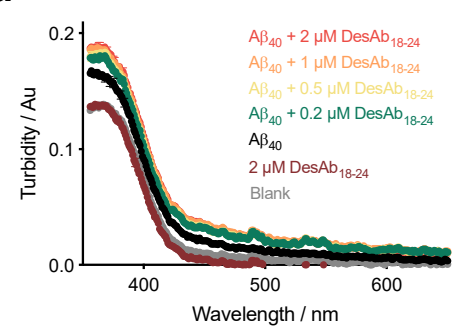

b

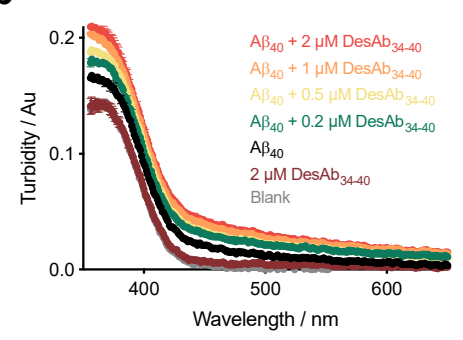

C

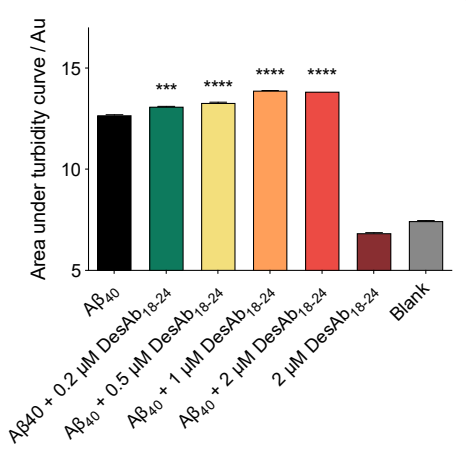

d

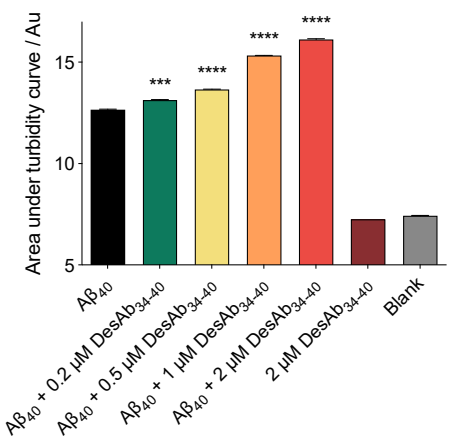

e

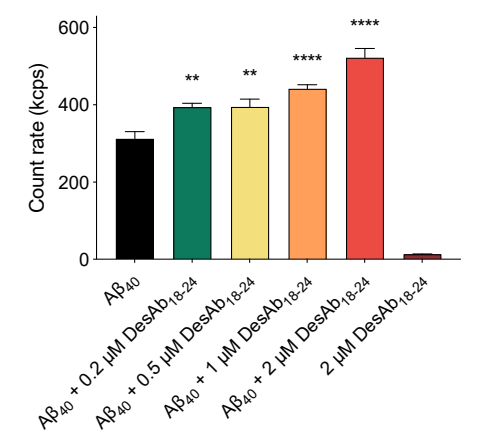

f

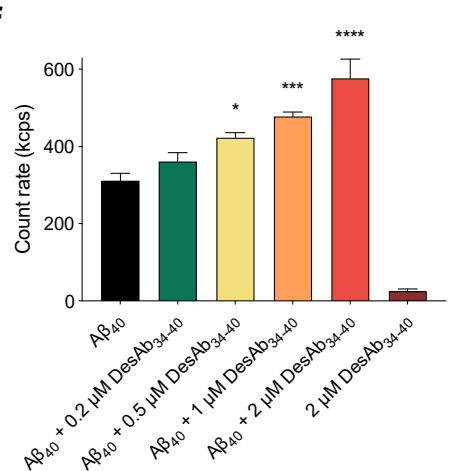

Figure 3. DesA $b_{18-24}$ and Des $A b_{34-40}$ increase the size of stabilized $A \beta_{40}$ oligomers. (a,b) Turbidity measurements for oligomers of $\mathrm{A} \beta_{40}$ incubated at a concentration of $10 \mu \mathrm{M}$ in the absence (black) or presence of $0.2 \mu \mathrm{M}$ (green), $0.5 \mu \mathrm{M}$ (yellow), $1 \mu \mathrm{M}$ (orange) and $2 \mu \mathrm{M}$ (red) of DesAb $\mathrm{b}_{18-24}$ (a) and $\operatorname{DesAb}_{34-40}(\mathbf{b})$. Samples are identical to those shown in Figure 2. (c,d). Turbidity traces analyzed by area under the curve integration. Note that the highest concentration of DesAbs tested ( $2 \mu \mathrm{M}$, dark red) did not significantly change the absorbance relative to the blank (ANS, grey). Error bars denote SEM of duplicate spectra. $(\mathbf{e}, \mathbf{f})$ SLS measurements in the absence of ANS and the presence of A $\beta_{40}$ oligomers and increasing concentrations of the designed antibodies. Note negligible scattering from the highest ratio of the DesAbs tested in the absence of oligomers. Error bars denote SEM of six measurements. In all panels, the symbols ${ }^{*}{ }^{* *},{ }^{* * *}$ and ${ }^{* * * *}$ indicate $p<0.05,0.01,0.001$ and 0.0001 , respectively. Samples containing oligomers were analyzed by one-way ANOVA followed by Bonferroni's multiple comparison test relative to oligomers in buffer.

In order to validate the increase in size with an ANS-free independent method, samples were incubated under the same conditions and measured using static light scattering (SLS). In agreement with 
the turbidity measurements, we found that the incubation of the stabilized oligomers in the presence of increasing concentrations of DesAbs resulted in augmented light scattering (Figure 3e,f). As additional evidence of a size increase of the aggregates in solution, we also employed sedimentation-based dot-blot assays. In these measurements, larger aggregates are postulated to sediment more readily than unmodified small oligomers. Oligomers were incubated as previously described with and without antibodies, centrifuged $\left(13,000 \mathrm{rcf}, 20^{\circ} \mathrm{C}, 15 \mathrm{~min}\right)$, concentrated during resuspension, and deposited atop a nitrocellulose membrane. Minimal protein was deposited in the samples containing oligomers in the absence of antibodies, as recognized using the anti-A $\beta$ antibody $6 \mathrm{E} 10$. The presence of the DesAbs, however, resulted in an increase of $\mathrm{A} \beta_{40}$ sedimentation with dose dependence (Supplementary Figure S2). Taken together, the turbidimetry, SLS, and sedimentation measurements support the conclusion that the DesAbs significantly increase the size of the $A \beta_{40}$ oligomers in solution. We note that recent work on oligomers demonstrated that protein misfolded oligomer toxicity is independent of their secondary structures [44], and we therefore elected to focus on the size-hydrophobicity-toxicity relationship in detail.

To directly visualize the size and morphology of these oligomer clusters, we next investigated the oligomer-DesAb $\mathrm{B}_{34-40}$ complex by phase-controlled atomic force microscopy (AFM) $[45,46]$. Stabilized $A \beta_{40}$ oligomers were incubated as previously described at a concentration of $10 \mu \mathrm{M}$ (in monomer equivalents) in the absence and presence of $2 \mu \mathrm{M}$ DesAb $34-40\left(2 \mathrm{~h}, 20^{\circ} \mathrm{C}\right)$, and diluted in buffer by a factor of 20 before conventional, manual deposition atop an atomically flat mica surface. In the absence of DesAb $\mathrm{B}_{34-40}$, oligomers were $1-5 \mathrm{~nm}$ in height (Figure 4 ), in agreement with previous characterizations [42]. In the presence of DesAb $\mathrm{Ab}_{34-40}$, clusters ranging in cross-sectional height from 20 to $50 \mathrm{~nm}$ were readily observed, in good agreement with the size results observed in the bulk experiments (Figure 4).
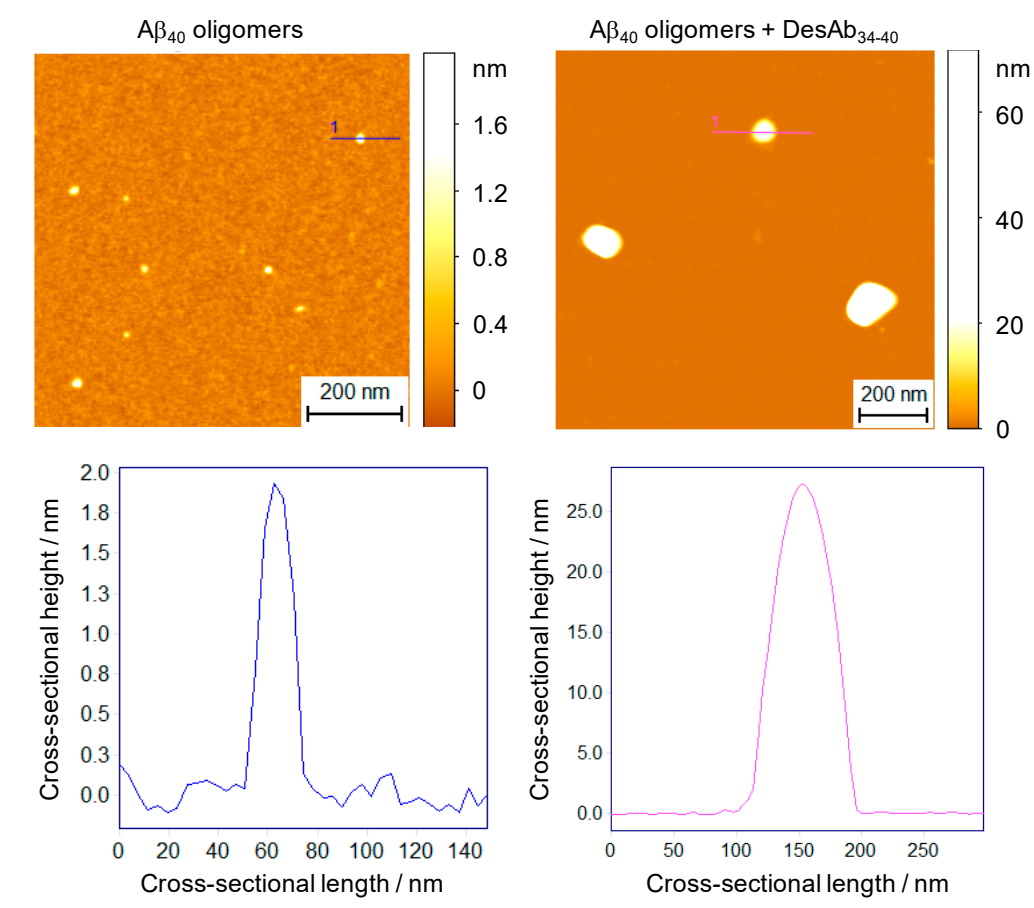

Figure 4. Phase-controlled AFM measurements of the oligomer-antibody complexes. A $\beta_{40}$ oligomers were incubated at a concentration of $10 \mu \mathrm{M}$ in the absence (left) and presence of $2 \mu \mathrm{M}$ DesAb ${ }_{34-40}$ (right) and diluted 20-fold in buffer before deposition. Large oligomeric clusters (white aggregates in the 3D AFM maps) were observed in the presence of DesAb $\mathrm{b}_{34-40}$. Representative aggregate heights are shown below each 3D color plot for the indicated cross-sectional profiles. Scale bars, $0.2 \mu \mathrm{m}$. 


\subsection{Trodusquemine Binds Stabilized $A \beta_{40}$ Oligomers and Increases their Hydrophobic Surface Area}

The natural product trodusquemine has been characterized for its ability to displace protein misfolded oligomers from the surfaces of cell membranes, resulting in a marked decrease in oligomer-induced cytotoxicity towards neuroblastoma cells. Its protective effects were observed at physiological concentrations of this aminosterol, corresponding to equimolar or substoichiometric concentrations of the molecule relative to oligomers, where greater than equimolar concentrations of trodusquemine demonstrated its intrinsic toxicity to cells [29]. Further, we previously observed that trodusquemine can increase the size and hydrophobicity of $\mathrm{A} \beta_{42}$ oligomers at superstoichiometric concentrations, whereas the effects were not significant at substoichiometric concentrations [29].

To build on this result and to increase the size and hydrophobicity of $A \beta_{40}$ oligomers similarly to our DesAbs, and thus to obtain a control case for this study, we incubated stabilized $\mathrm{A} \beta_{40}$ oligomers at a concentration of $5 \mu \mathrm{M}$ (in monomer equivalents) in $20 \mathrm{mM}$ Tris, $100 \mathrm{mM} \mathrm{NaCl}, \mathrm{pH}$ 7.4, in the absence and presence of increasing concentrations of trodusquemine $\left(0-50 \mu \mathrm{M}, 1 \mathrm{~h}\right.$ at $\left.20^{\circ} \mathrm{C}\right)$. After incubation, ANS was added to a final concentration of $15 \mu \mathrm{M}$ (i.e., 3 -fold excess). The incubation of $\mathrm{A} \beta_{40}$ oligomers with trodusquemine increased the maximum fluorescence intensity and caused a further blue-shift of its wavelength, with a well-defined dose dependence (Figure 5a), indicating a prominent increase in solvent-exposed hydrophobicity. As a control, both the intensity and maximum wavelength of free ANS were unchanged in the absence of oligomers and in the presence of the highest concentration of trodusquemine (i.e., $50 \mu \mathrm{M}$ ).

The incubation of stabilized $\mathrm{A} \beta_{40}$ oligomers with trodusquemine and ANS also resulted in a well-defined increase in turbidity with a clear dose dependence (Figure 5b). Using SLS measurements in the absence of ANS, we also observed a dose-dependent increase in the extent of light scattered upon the incubation of the oligomers in the presence of increasing concentrations of trodusquemine (Figure 5c). Negligible turbidity and light scattering were measured for $50 \mu \mathrm{M}$ trodusquemine in the absence of oligomers (Figure $5 b, c$ ), indicating that the molecule does not form large clusters under these conditions, and does not contribute significantly to the observations in the presence of $A \beta_{40}$ oligomers. The relative change in the extent of light scattered upon the interaction of increasing concentrations of trodusquemine with the oligomers is in good agreement with the turbidity data.

The trodusquemine-mediated modification of stabilized $A \beta_{40}$ oligomers was also studied using phase-controlled AFM $[45,47,48]$. Sample deposition was carried out using a recently developed microfluidic spraying device [49]. The utilization of this methodology affords the advantage of spraying microdroplets atop the mica substrate at subpicoliter volumes, which evaporate on the timescale of milliseconds, thereby avoiding artefacts due to surface mass transport processes caused by drying [49], which are particularly likely while drying significant concentrations of a polyvalent small molecule in addition to oligomers. Stabilized $\mathrm{A} \beta_{40}$ oligomers were incubated as previously described at a concentration of $5 \mu \mathrm{M}$ in the absence and presence of a 5 -fold excess of trodusquemine $\left(1 \mathrm{~h}, 20^{\circ} \mathrm{C}\right)$ and subsequently diluted by a factor of five in buffer prior to spraying atop an atomically flat mica surface (Figure $5 \mathrm{~d}$ ). In the absence of molecules, the cross-sectional heights of the oligomers were typically 1-5 $\mathrm{nm}$ in height, in agreement with previous reports [42]. Upon the addition of a 5-fold excess of molecule, the presence of large clustered species was observed with cross-sectional heights ranging from approximately 20 to $40 \mathrm{~nm}$ (Figure 5e), in good agreement with the turbidity and SLS results observed in the bulk experiments. 
a

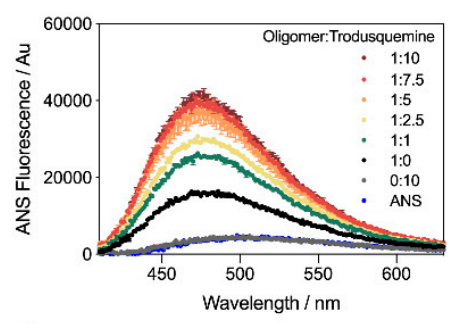

d

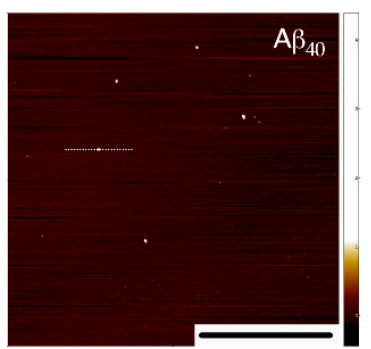

b

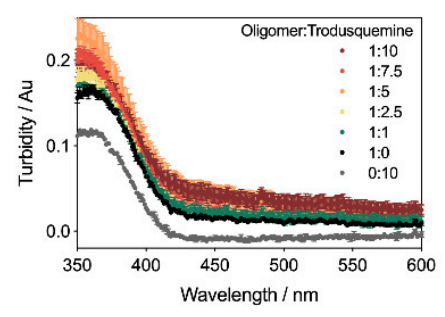

e

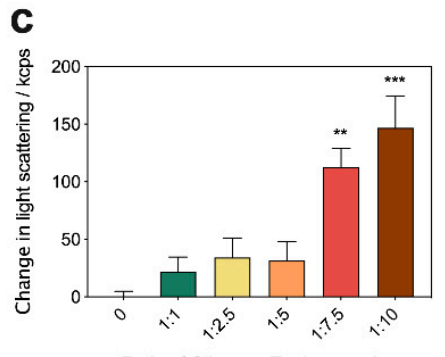

Ratio of Oligomer:Trodusquemine

Figure 5. Trodusquemine increases the hydrophobicity and size of stabilized $A \beta_{40}$ oligomers. $(\mathbf{a}, \mathbf{b})$ Oligomers were incubated at a concentration of $5 \mu \mathrm{M}$ in the absence (black) and presence of $5 \mu \mathrm{M}$ (green), $12.5 \mu \mathrm{M}$ (yellow), $25 \mu \mathrm{M}$ (orange), $37.5 \mu \mathrm{M}$ (red), and $50 \mu \mathrm{M}$ (brown) trodusquemine and monitored for the binding of ANS (a) and turbidity absorbance (b). Grey traces indicate the effect of $50 \mu \mathrm{M}$ trodusquemine (TRO) (i.e., the highest ratio tested) in the absence of oligomers. Error bars denote SEM of duplicate spectra. (c) SLS measurements after oligomer incubation in the presence of increasing concentrations of trodusquemine. Data are shown as the change in light scattered. Error bars represent the SEM of three replicates, and the symbols ${ }^{* *}$ and ${ }^{* * *}$ indicate $p<0.01$ and 0.001 , respectively. Samples containing oligomers were analyzed by one-way ANOVA followed by Bonferroni's multiple comparison test relative to oligomers in buffer. (d) AFM maps for oligomers incubated in the absence (left panel) or presence of a 5-fold excesses of trodusquemine (right panel). Scale bars, $2 \mu \mathrm{m}$. Upper limits on the color scales are circa $4.2 \mathrm{~nm}$ for $\mathrm{A} \beta_{40}$ oligomers alone (left panel) and $35 \mathrm{~nm}$ for the $\mathrm{A} \beta_{40}$ oligomer-trodusquemine complex (right panel). (e) Representative cross-sectional heights of oligomers in the absence (left panel) and presence of trodusquemine (right panel). Dotted white lines in indicate the corresponding sampled cross section from (d).

\subsection{The DesAbs do not Change the Toxicity of $A \beta_{40}$ Oligomers for Human Neuroblastoma Cells}

To assess whether the increase in oligomer size and hydrophobicity induced by DesAbs and trodusquemine resulted in changes of oligomer toxicity, cell viability experiments using the MTT reduction assay were performed using SH-SY5Y human neuroblastoma cells in the presence of the oligomers. Stabilized $\mathrm{A} \beta_{40}$ oligomers ( $5 \mu \mathrm{M}$, in monomer equivalents) were formed and incubated in the absence and presence of increasing concentrations of DesAb $\mathrm{b}_{18-24}$ and DesAb $\mathrm{b}_{34-40}(0.25 \mu \mathrm{M}, 0.5 \mu \mathrm{M}$ and $1 \mu \mathrm{M}$ ) for $1 \mathrm{~h}$ at $37^{\circ} \mathrm{C}$, and subsequently added to the cell culture medium of SH-SY5Y cells for $24 \mathrm{~h}$ at $37^{\circ} \mathrm{C}$. These concentrations were selected to match the biophysical experiments. The cells were also treated with the corresponding concentrations of antibodies in the absence of oligomers, which was not observed to induce deleterious changes in cellular viability. $A \beta_{40}$ oligomers were found to decrease the viability of the cells by $23.4 \pm 3.6 \%$, and this toxicity was not changed significantly upon the addition of either DesAb when co-incubated with oligomers at these concentrations (Figure 6a). 
a

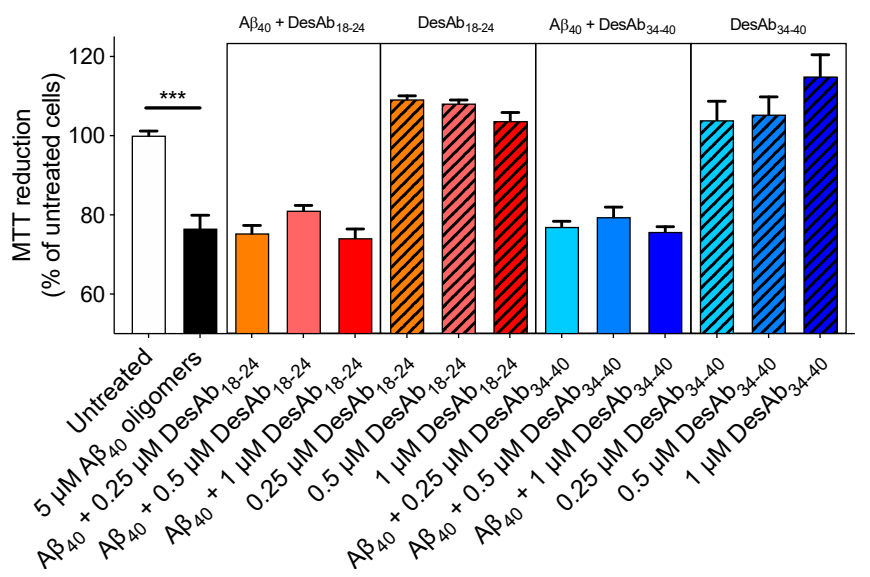

b

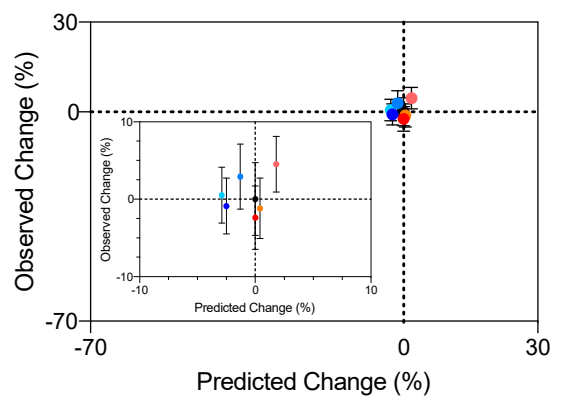

Figure 6. The interaction of the DesAbs with stabilized $A \beta_{40}$ oligomers does not change their toxicity. (a) Stabilized oligomers of $A \beta_{40}$ were resuspended in the cell culture medium at a concentration of $5 \mu \mathrm{M}$ and incubated in the absence (black plain bar) or presence of increasing concentrations $(0.25$, 0.5 and $1 \mu \mathrm{M}$ ) of DesAb $\mathrm{b}_{18-24}$ (red plain bars) and DesAb $\mathrm{b}_{34-40}$ (blue plain bars) for $1 \mathrm{~h}$ at $37^{\circ} \mathrm{C}$ and then added to the cell culture medium of SH-SY5Y cells for $24 \mathrm{~h}$. The cells were also treated with corresponding concentrations of the antibodies pre-incubated in the absence of oligomers (dashed bars with corresponding colors). Error bars indicate SEM of six replicates. The symbol ${ }^{* * *}$ indicates $p<0.001$ (unpaired, two-tailed Student's $t$-test). All conditions containing both antibodies and oligomers were not significantly different in comparison to cells treated with oligomers alone (individual antibody groups were compared by one-way ANOVA using Bonferroni's multiple comparisons relative to cells treated with oligomers alone). (b) The wavelength of maximum ANS fluorescence as a probe of solvent exposed hydrophobicity and the Rayleigh ratios from SLS measurements as a measure of size were used to predict the change in MTT reduction caused by oligomers in the absence and presence of the various concentrations of DesAbs (Supplementary Table S1) as previously described [30]. The predicted values were plotted against the observed ones from (a). The formula predicts that the DesAb-mediated increase in both hydrophobicity and size of $\mathrm{A} \beta_{40}$ oligomers does not significantly change the toxicity, as was observed experimentally.

We then compared the observed experimental changes in cell viability upon the addition of various concentrations of DesAbs to $A \beta_{40}$ oligomers to the predicted changes, where the latter was estimated using a previously defined formula [30] (Figure 6b and Supplementary Table S1). The comparison indicated that the toxicity of stabilized $A \beta_{40}$ oligomers was neither predicted nor observed to change upon the addition of these concentrations of DesAb $18-24$ and DesAb $b_{34-40}$. This might appear surprising, as oligomer size and hydrophobicity are known to be key determinants of oligomer toxicity [30-36]. However, increases in size and hydrophobicity are predicted to decrease and increase oligomer toxicity, respectively, resulting in counteracting effects and no overall change in toxicity. The highly significant correlations found between $A \beta_{40}$ oligomer size and hydrophobicity in the presence of designed antibodies and trodusquemine indicate that these agents cause paired increases of both parameters (Figure 7), resulting in no significant effect on the toxicity of the $\mathrm{A} \beta_{40}$ oligomers (Supplementary Table S1).

We also measured the toxicity of the oligomers with a greater concentration (i.e., $10 \mu \mathrm{M}$, monomer equivalents) and at the same molar ratios studied above, i.e., $0.5 \mu \mathrm{M}, 1 \mu \mathrm{M}$ and $2 \mu \mathrm{M}$ antibodies (Supplementary Figure S3). Again, the addition of DesAb ${ }_{18-24}$ did not alter the toxicity of the stabilized $\mathrm{A} \beta_{40}$ oligomers, suggesting that the concentration of toxic species is not likely to result in different biological activity of the antibodies. Collectively, these results suggest that the ability of the antibodies to cluster the oligomers into larger and more hydrophobic species does not change the toxicity of the aggregates, which agrees well with the predictions (Supplementary Table S1). 
a

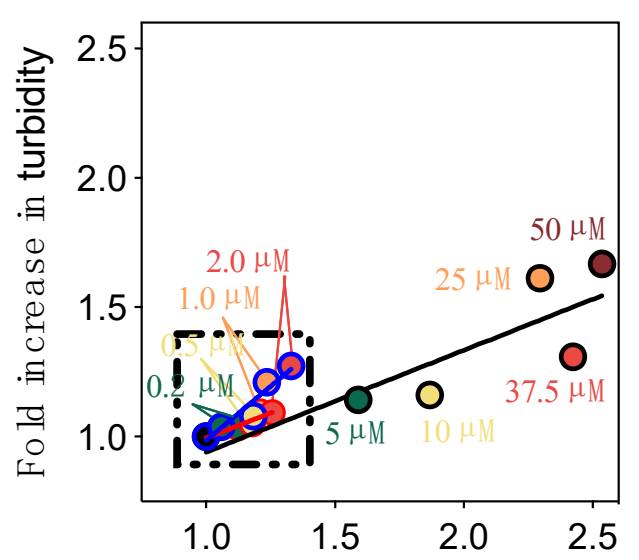

Fo ld increase in ANS flourescence b

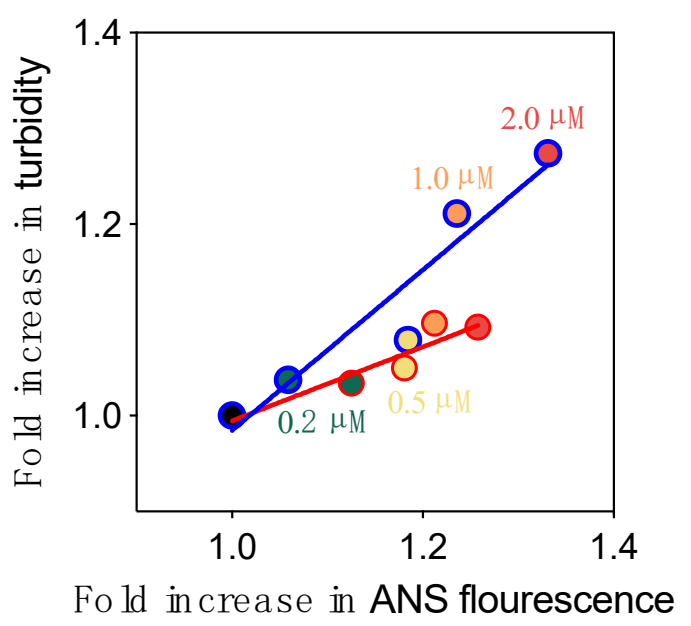

Figure 7. Size-hydrophobicity relationship for increasing concentrations of the designed antibodies and trodusquemine. (a) Linear fits between size and solvent-exposed hydrophobicity for increasing concentrations of DesAb $\mathrm{A}_{34-40}$ (blue line, slope $=0.84 \pm 0.15, \mathrm{R}=0.95$ ), DesAb $18-24$ (red, slope $=0.38 \pm$ $0.08, \mathrm{R}=0.86$ ), and trodusquemine ( $\mathrm{TRO}$, black line, slope $=0.39 \pm 0.12, \mathrm{R}=0.86$ ). (b) Zoomed in view of panel a for the designed antibodies.

It was not possible to carry out the MTT assays for $\mathrm{A} \beta_{40}$ oligomers incubated with trodusquemine at the superstoichiometric concentrations that are necessary to observe a significant clustering effect of the oligomers [29]. Indeed, the molecule alone was shown to be toxic to cells at concentrations greater than a few micromolar [29]. Such an experiment would further fail to account for the unique ability of trodusquemine to bind to cell membranes and displace $\mathrm{A} \beta$ oligomers.

\section{Discussion}

$A \beta$ oligomers are highly cytotoxic species associated with the aggregation reaction of $A \beta$, which is central to the onset and development of AD [4-7]. Extensive past work has been carried out to investigate the structure-toxicity relationship of these oligomers, for example through the use of cross-linking to generate stabilized oligomeric forms [50-52]. More specifically, the toxicity of aberrant oligomeric protein aggregates has been previously described as a function of size and hydrophobicity for multiple proteins, where the most cytotoxic aggregates are generally small and have extensive hydrophobic surface exposure $[30,32,35]$. These physiochemical properties play a central role in the ability of oligomers to cause cellular dysfunction, which can result from the uptake of the oligomeric proteins into the cell [53-55], or directly by the oligomer-induced perturbation of cell membranes $[3,36]$. Here, we utilized rationally designed antibodies (DesAbs) to probe the structure-toxicity relationship of $\mathrm{Zn}^{2+}$-stabilized $\mathrm{A} \beta_{40}$ oligomers, which we adopted as models of the $\mathrm{A} \beta$ oligomers that may form in synaptic regions where $\mathrm{Zn}^{2+}$ tends to be abundant [42]. We used these DesAbs as molecular tools, following our previous illustrations of their applications for diagnostic [27] or therapeutic purposes [18].

An increase in size alone, in the absence of other physicochemical changes, has been well documented to suppress oligomer cytotoxicity. Indeed, high concentrations of molecular chaperones, including clusterin and a $\beta$-crystallin, have been shown to reduce the cellular toxicity of oligomers comprised of $\mathrm{A} \beta_{42}, \mathrm{HypF}-\mathrm{N}$, and islet amyloid polypeptide through a clustering-based mechanism $[31,33,35]$. The reduction in toxicity mediated by clustering was therefore attributed to a prominent decrease in the surface to volume ratio of the aggregates, thereby reducing the diffusibility of the oligomers and limiting their interaction with the cellular membrane [32,35]. In the case of the DesA $b_{18-24}$ and DesAb ${ }_{34-40}$, and trodusquemine at superstoichiometric concentrations, $\mathrm{A} \beta_{40}$ oligomer size was significantly increased upon interaction with the antibodies and the aminosterol. 
In addition to size, hydrophobicity is a key determinant of oligomer cytotoxicity [34,36]. A decrease in hydrophobicity is associated with lower cytotoxicity. At superstoichiometric concentrations of clusterin and a $\beta$-crystallin relative to HypF-N oligomers, these molecular chaperones were shown to be able to mask the solvent exposure of protein misfolded oligomers in the absence of significant oligomer size increases $[32,35]$. The corresponding decrease in cellular toxicity was explained by their lessened affinity for cell membranes induced by the lowering of oligomer solvent-exposed hydrophobicity. For DesAb $\mathrm{Ab}_{18-24}$ and DesAb $\mathrm{b}_{34-40}$ and trodusquemine at superstoichiometric concentrations, however, $\mathrm{A} \beta_{40}$ oligomer hydrophobicity was significantly increased upon interaction with the antibodies and molecules.

The DesAbs modified the structure of the oligomers in a way that is expected to increase their cytotoxicity by increasing their hydrophobicity. At the same time, the DesAbs could also be expected to decrease the toxicity of the oligomers by increasing their size. Thus, by using the DesAbs as molecular tools, we leveraged a well-described size-hydrophobicity formula [30] to predict that these physiochemical changes would cancel each other in terms of the resulting toxicity of the oligomers. Experimentally, we confirmed these predictions by observing that these changes offset each other, as manifested by negligible changes in oligomer toxicity to the neuroblastoma cells upon interaction with the DesAbs (Figure 8).

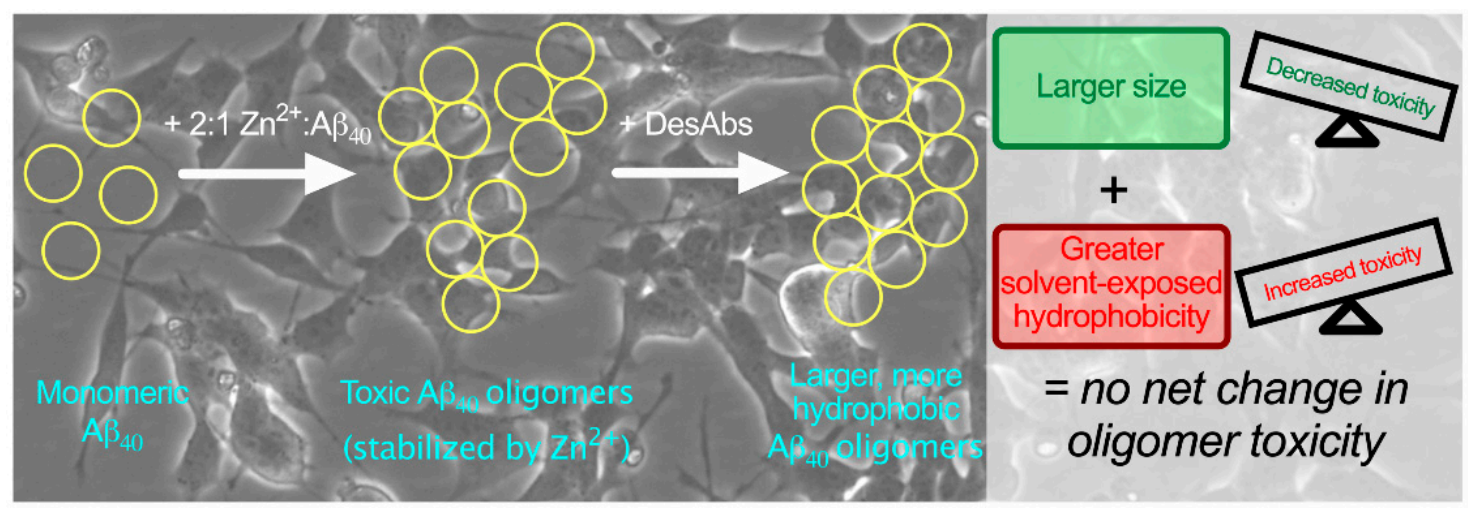

Figure 8. We have used rationally designed antibodies (DesAbs) as molecular tools to investigate the size-hydrophobicity-toxicity relationship of $A \beta_{40}$ oligomers. Incubation with DesAbs increased the size and hydrophobicity of $\mathrm{Zn}^{2+}$-stabilized $\mathrm{A} \beta_{40}$ oligomers. These physicochemical changes decrease and increase the toxicity of these particular model oligomers, respectively, resulting in no net overall change in their toxicity upon administration to cultured human neuroblastoma cells.

Trodusquemine and other molecules within the aminosterol family possess the unique ability to bind to cell membranes and prevent the deleterious association of oligomers via a displacement-based mechanism [29,56,57]. Given the absence of a protective effect of the DesAbs toward neuroblastoma cells when incubated alongside oligomers at the substoichiometric concentrations employed herein and as expected for a large antibody, they likely do not bind to cell membranes or displace protein misfolded oligomers. Moreover, the increases in both hydrophobicity and size induced by superstoichiometric concentrations of trodusquemine would be expected not to significantly change the cytotoxicity of the aggregates in the absence of the trodusquemine-induced displacement of oligomers; such an experiment could not be carried out given the intrinsic toxicity of trodusquemine at the concentrations necessary to observe these nonphysiologically relevant physiochemical changes [29]. Nonetheless, these findings show that the phenomena described herein extend beyond DesAb ${ }_{18-24}$ and $\operatorname{Des} \mathrm{Ab}_{34-40}$ to small molecules.

Based on these results, we anticipate that it may become possible in future systematic studies to obtain more insights into the structure-toxicity relationship of oligomers with new DesAbs targeting disease-related proteins. Utilization of in vitro assays capable of predicting the toxicity of oligomers by probing their structural and physicochemical properties could facilitate enhanced throughput 
preclinical drug discovery studies by limiting in part the need of more expensive and time-consuming cell culture experiments.

\section{Materials and Methods}

\subsection{Chemicals}

Trodusquemine was synthesized as a hydrochloride salt at a purity greater than $97 \%$, stored as a lyophilized powder $[58,59]$ and solubilized in water to a final concentration of $10 \mathrm{mM}$. Stocks were stored at $-20^{\circ} \mathrm{C}$ until use.

\subsection{Antibody Design, Expression and Purification}

Antibodies were computationally designed as previously described [18,37]. Complementary peptides designed to bind specific epitopes were grafted onto the CDR loops of domain antibodies [18,37]. The expression and purification of the antibodies were carried out as previously described [18]. In brief, DesAb constructs were expressed and purified using pRSET-B vector in E. coli Rosetta-gami 2 (DE3, Merck Millipore, Burlington, MA, USA), cells were grown, harvested and lysed, and the antibodies (circa $18 \mathrm{kDa}$ ) were purified using a $\mathrm{Ni}^{2+}$-NTA Superflow column (Qiagen, Hilden, Germany) [18]. The His-tagged antibodies were eluted by increasing the concentration of imidazole, and were subsequently dialyzed thoroughly in PBS. Protein concentration was determined by absorbance at $280 \mathrm{~nm}$ [18]. DesAb aliquots were stored at $-20{ }^{\circ} \mathrm{C}$ until use and never thawed more than once. The sequence of DesAb $\mathrm{Ab}_{18-24}$ is MRGSHHHHHHGMASMTGGQQMGRDLYDDDDKDPKLEVQLVESGGGLVQPGGSLRLSCAASGFN IKDTYIGWVRRAPGKGEEWVASIYPTNGYTRYADSVKGRFTISADTSKNTAYLQMNSLRAEDTAVYY CAAGSVFVGTEAEEEAAAWGQGTLVTVSSGT and that of DesAb ${ }_{34-40}$ is MRGSHHHHHHGMAS MTGGQQMGRDLYDDDDKDPKLEVQLVESGGGLVQPGGSLRLSCAASGFNIKDTYIGWVRRAPGKG EEWVASIYPTNGYTRYADSVKGRFTISADTSKNTAYLQMNSLRAEDTAVYYCAAGSIRETALLYEEEA AAWGQGTLVTVSSGT.

\subsection{Protein Expression and Chemical Kinetics}

The recombinant $A \beta(M 1-40)$ peptide (sequence MDAEFRHDSGY EVHHQKLVFF AEDVGSNKGA IIGLMVGGVV), denoted as $\mathrm{A} \beta_{40}$, was expressed in the Escherichia coli BL21 Gold (DE3) strain (Stratagene, San Diego, CA, USA) and purified as described previously [19]. Samples for kinetic experiments were prepared using standard reagents and methods with a final buffer composition of $20 \mathrm{mM}$ Tris, $100 \mathrm{mM} \mathrm{NaCl}, \mathrm{pH}$ 7.4. The concentration of the purified protein was quantified as it eluted off the column by integrating the peak area of absorbance with $\varepsilon_{280}=1400 \mathrm{~L} \mathrm{~mol}^{-1} \mathrm{~cm}^{-1}$ [60].

For kinetic experiments, samples were prepared with monomeric $A \beta_{40}$ at a concentration of $10 \mu \mathrm{M}$ in the absence or presence of $0.5 \mu \mathrm{M}, 1 \mu \mathrm{M}$, and $2 \mu \mathrm{M}$ DesAbs. All samples for the kinetic measurements were supplemented with $0.2 \mathrm{mM}$ ethylenediaminetetraacetic acid (EDTA) [29]. ThT was added from a $2 \mathrm{mM}$ stock to give a final concentration of $20 \mu \mathrm{M}$. All samples were prepared in low-binding Eppendorf tubes, and samples were analyzed in a 96-well half area, low-binding, clear-bottom PEG coated plate (Corning 3881, Sigma-Aldrich, St. Louis, MO, USA). ThT fluorescence was monitored in triplicate per sample and measured using bottom-optics in a plate reader (Fluostar Omega or Fluostar Optima from BMG Labtech, Aylesbury, UK) with 440 and $480 \mathrm{~nm}$ excitation and emission filters, respectively. Aggregation was initiated by transferring the 96 -well plate to the plate reader at $37^{\circ} \mathrm{C}$ under quiescent conditions. The data shown are representative of three independent experiments that gave consistent results. 


\subsection{Preparation of the Stabilized $A \beta_{40}$ Oligomers}

First, $1 \mathrm{mg}$ of lyophilized $\mathrm{A} \beta_{40}$ was solubilized overnight in $300 \mu \mathrm{L}$ hexafluoroisopropanol (HFIP) at $4{ }^{\circ} \mathrm{C}$. Solvent was evaporated with a gentle flow of nitrogen gas, and the protein was resuspended in DMSO to $2.2 \mathrm{mM}$. Two sonication steps of $10 \mathrm{~min}$ were preformed, after which the protein was diluted at a concentration of $100 \mu \mathrm{M}$ in $20 \mathrm{mM}$ sodium phosphate buffer, $200 \mu \mathrm{M} \mathrm{ZnCl}_{2}, \mathrm{pH} 6.9$ for $20 \mathrm{~h}$ at $20^{\circ} \mathrm{C}$. Samples were centrifuged $\left(15,000 \mathrm{rcf}, 20^{\circ} \mathrm{C}, 15 \mathrm{~min}\right)$ to a pellet and the supernatant was removed [42]. Oligomers were resuspended in buffer ( $20 \mathrm{mM}$ Tris, $100 \mathrm{mM} \mathrm{NaCl}, \mathrm{pH} 7.4)$ with thorough mixing.

\subsection{ANS Binding Measurements}

First, $10 \mu \mathrm{M} \mathrm{A} \beta_{40}$ oligomers (monomer equivalents) were incubated $\left(2 \mathrm{~h}, 20^{\circ} \mathrm{C}\right)$ in the absence and presence of increasing concentrations of DesAbs $(20 \mathrm{mM}$ Tris, $100 \mathrm{mM} \mathrm{NaCl}, \mathrm{pH} 7.4)$ at. Samples containing trodusquemine were incubated $\left(1 \mathrm{~h}, 20^{\circ} \mathrm{C}\right)$ at an oligomer concentration of $5 \mu \mathrm{M}(20 \mathrm{mM}$ Tris, $100 \mathrm{mM} \mathrm{NaCl}, \mathrm{pH}$ 7.4) in the absence or presence of the small molecule at concentrations ranging from $5 \mu \mathrm{M}$ to $50 \mu \mathrm{M}$. Subsequently, ANS was added to a final concentration of $30 \mu \mathrm{M}$ or $15 \mu \mathrm{M}$, respectively (i.e., 3-fold excess dye in both cases). Emission spectra were recorded using a plate reader (BMG Labtech) with excitation at $380 \mathrm{~nm}$. Duplicate samples are representative of three independent experiments that gave consistent results. All spectra were background subtracted to the buffer.

\subsection{Turbidimetry Measurements}

Samples from the ANS preparation were analyzed using a plate reader (BMG Labtech) with spectral scanning. Duplicate samples are representative of three independent experiments that gave consistent results. All spectra were background subtracted to the buffer.

\subsection{SLS}

First, $10 \mu \mathrm{M} \mathrm{A} \beta_{40}$ oligomers (monomer equivalents) were incubated for $2 \mathrm{~h}$ in the absence and presence of increasing concentrations of DesAbs $(20 \mathrm{mM}$ Tris, $100 \mathrm{mM} \mathrm{NaCl}, \mathrm{pH} 7.4)$ at $20{ }^{\circ} \mathrm{C}$. SLS measurements were performed using the Malvern Zetasizer Nano $\mathrm{S}$ instrument (Malvern Panalytical, Malvern, UK) with fixed parameters (attenuator 9, cell position $4.65 \mathrm{~mm}$ ), equipped with a Peltier temperature controller $\left(25^{\circ} \mathrm{C}\right)$. A low volume $(70 \mu \mathrm{L})$ disposable cuvette was used (BrandTech Scientific, Essex, CT, USA). Samples containing trodusquemine were incubated $\left(1 \mathrm{~h}, 20^{\circ} \mathrm{C}\right)$ at an oligomer concentration of $5 \mu \mathrm{M}(20 \mathrm{mM}$ Tris, $100 \mathrm{mM} \mathrm{NaCl}, \mathrm{pH} 7.4)$ in the absence or presence of the small molecule at concentrations ranging from $5 \mu \mathrm{M}$ to $50 \mu \mathrm{M}$.

\subsection{Sedimentataion-Based Dot Blot Assays}

$\mathrm{A} \beta_{40}$ oligomers were prepared at a concentration of $10 \mu \mathrm{M}$ (monomer equivalents) and incubated in the absence or presence of 0.5, 1.0 and $2 \mu \mathrm{M}$ DesAbs, as described above. For sedimentation measurements, $50 \mu \mathrm{L}$ aliquots of samples were centrifuged (Eppendorf Centrifuge $5424 \mathrm{R}$, Hambrug, Germany) for $10 \mathrm{~min}$ at $13,000 \times \mathrm{g}$ and $20^{\circ} \mathrm{C}$. Supernatant was removed and protein was thoroughly resuspended in $20 \mu \mathrm{L}$ buffer prior to spotting the nitrocellulose membrane ( $2 \mu \mathrm{L}$ per spot) (Whatman, pore size of $0.2 \mu \mathrm{m}$, GE Healthcare). Membranes were blocked with skim milk (Sigma-Aldrich) for $1 \mathrm{~h}$, after which time the primary antibody 6E10 (803001, BioLegend, San Diego, CA, USA) was incubated at a 1:1000 dilution overnight at $4{ }^{\circ} \mathrm{C}$. The Alexa488-conjugated secondary antibody (anti-mouse, Life technologies, Carlsbad, CA, USA) was subsequently incubated for $1 \mathrm{~h}$ at a 1:5000 dilution at $20{ }^{\circ} \mathrm{C}$. Fluorescence was detected using a Typhoon Trio Imager (GE Healthcare, Chicago, IL, USA). Membranes were prepared in duplicate, and representative images are shown. ImageJ was used for quantifications. 


\subsection{Antibody Binding Dot Blot Assays}

In order to assess the binding of the DesAbs, dot blots were prepared as follows: $4 \mu \mathrm{M}$ solutions of DesAb were spotted $(3.5 \mu \mathrm{L}$ ) onto a $0.2 \mu \mathrm{m}$ pore size nitrocellulose membrane corresponding to total deposited antibody of 50, 25, 12.5 and $6.3 \mu \mathrm{g}$ DesAb. The blots were blocked in PBS, 5\% BSA overnight at $4{ }^{\circ} \mathrm{C}$. Subsequently, they were incubated in solutions containing $5 \mu \mathrm{M} \mathrm{A} \beta_{40}$ oligomers in PBS overnight at $4{ }^{\circ} \mathrm{C}$. Blots were then probed with the mouse monoclonal anti-amyloid $\beta$ antibody (clone 6E10) (1:2000 dilution; Absolute Antibody Ltd., Oxford, UK) overnight at $4{ }^{\circ} \mathrm{C}$, and then with goat anti-mouse $\operatorname{IgG}(\mathrm{H}+\mathrm{L})$ secondary antibody and AF488 conjugate (1:5000 dilution; Life Technologies) for $2 \mathrm{~h}$ at $25^{\circ} \mathrm{C}$.

\subsection{Atomic Force Microscopy}

$\mathrm{A} \beta_{40}$ oligomers $(10 \mu \mathrm{M}$, monomer equivalents) were incubated in the absence and presence of $2 \mu \mathrm{M}$ DesAb $34-40$, as previously described, and diluted by a factor of 20 before deposition atop an atomically flat mica surface. AFM samples preparation was carried out at room temperature by deposition of a $10 \mu \mathrm{L}$ drop of solution deposited for $2 \mathrm{~min}$ to a freshly-cleaved mica surface. Salt was washed with water, and samples were dried by the gentle flow of nitrogen and stored in a sealed container until imaging using a Park NX10 AFM (Park Systems, Suwon, Korea) with scan rates $<0.4 \mathrm{~Hz}$ and PPP-NCHR cantilevers with an $8 \mathrm{~nm}$ nominal radius (Nanosensors, Neuchatel, Switzerland). To visualize the trodusquemine-oligomer complex, $\mathrm{A} \beta_{40}$ oligomers $(5 \mu \mathrm{M}$, monomer equivalents) were incubated in the absence and presence of $25 \mu \mathrm{M}$ trodusquemine for $1 \mathrm{~h}$ as previously described. These samples were diluted in buffer by a factor of five and subsequently sprayed at $100 \mu \mathrm{L} / \mathrm{h}$ for $1 \mathrm{~min}$. at room temperature using a recently described microfluidic device [49] atop an atomically flat mica surface. Samples were stored in a sealed container until imaging using a JPK Nanowizard2 AFM with scan rates $<0.3 \mathrm{~Hz}$ and a silicon tip with a $10 \mathrm{~nm}$ nominal radius $\left(2 \mathrm{~N} \mathrm{~m}^{-1}\right.$, MikroMasch, Wetzlar, Germany). For all samples, standardized scanning conditions were established and maintained while measuring the samples, such that a phase change on the order of $\approx \Delta 20^{\circ}$ upon the interaction of the tip with the sample was not exceeded; changes corresponding to dissipated energy during the sample-tip interactions in excess of this threshold can lead to artifacts in the height quantification caused by deformations induced in the sample by the tip $[29,45,61]$. Three-dimensional maps were flattened using the SPIP (Image Metrology, Horsholm, Denmark) software, and the cross-sectional height of unique aggregates was compared [47,61].

\subsection{Neuroblastoma Cell Cultures}

Human SH-SY5Y neuroblastoma cells (Sigma-Aldrich, origin from A.T.C.C., Manassas, VA, USA) were cultured in DMEM, F-12 HAM with 25 mM HEPES and $\mathrm{NaHCO}_{3}$ (1:1) and supplemented with $10 \%$ FBS, $1 \mathrm{mM}$ glutamine and $1.0 \%$ antibiotics. Cell cultures were maintained in a $5 \% \mathrm{CO}_{2}$ humidified atmosphere at $37^{\circ} \mathrm{C}$, and grown until they reached $80 \%$ confluence for a maximum of 20 passages [62,63]. Cell lines were authenticated, and tested negative for mycoplasma contaminations. To count the cells, old medium was removed from the flask and the cells were detached using trypsin (Thermo Fisher, Waltham, MA, USA). An equal volume of medium was used to neutralize the trypsin once the cells were fully in suspension, as monitored under an inverted microscope. Cells were centrifuged gently to a pellet $\left(1500 \mathrm{rpm}, 5 \mathrm{~min}, 25^{\circ} \mathrm{C}\right.$ ) and resuspended in fresh medium. Then, $10 \mu \mathrm{L}$ cells were mixed with $10 \mu \mathrm{L}$ trypan blue stain to stain dead cells $(0.4 \%$, Thermo Fisher) and counted using the Countess II (Thermo Fisher).

\subsection{MTT Reduction Assay}

$\mathrm{A} \beta_{40}$ oligomers ( 5 or $10 \mu \mathrm{M}$ in monomer equivalents, as indicated) were incubated in the absence and presence of 20:1 to 5:1 molar ratios of the designed antibodies in cell culture medium for $1 \mathrm{~h}$ at $37^{\circ} \mathrm{C}$ under shaking conditions, and then added to the cell culture medium of SH-SY5Y cells seeded in 
96-well plates for $24 \mathrm{~h}$. The 3-(4,5-dimethylthiazol-2-yl)-2,5-diphenyltetrazolium bromide (MTT) assay was performed as previously described [63,64].

\subsection{Statistics and Data Availability}

Statistical analyses were performed in GraphPad Prism 8 (GraphPad Software, La Jolla, CA, USA). All error bars denote standard error of the mean (SEM). One-way ANOVA was used for multiple comparisons as a function of increasing concentration of DesAbs relative to oligomers incubated in buffer or cell culture medium (with Bonferroni's multiple comparisons test). Comparisons between untreated cells and oligomer-exposed cells were performed using an unpaired, two-tailed Student's $t$-test. $p<0.05$ was accepted as statistically significant. Data are available from the authors upon request.

Supplementary Materials: Supplementary materials can be found at http://www.mdpi.com/1422-0067/21/12/ 4542/s1.

Author Contributions: Conceptualization, R.L., B.M., P.S., F.S.R., C.M.D., F.A.A. and M.V.; methodology, R.L., B.M., R.C., S.C., F.S.R. and F.A.A.; writing-original draft preparation, R.L., F.C., F.A.A. and M.V.; supervision, R.L., C.M.D., F.A.A. and M.V.; formal analysis, R.L., B.M., R.C., S.C. (Shianne Chhangur), A.K.W., R.P.K., J.A.A., S.C. (Sean Chia), J.H., P.S., J.R.K., F.S.R., F.C., F.A.A. and M.V.; writing-review and editing, R.L., B.M., R.C., S.C. (Shianne Chhangur), A.K.W., R.P.K., J.A.A., S.C. (Sean Chia), J.H., P.S., J.R.K., F.S.R., F.C., F.A.A. and M.V. All authors have read and agreed to the published version of the manuscript.

Funding: This work was supported by the Centre for Misfolding diseases (R.L., B.M., R.C., S.C. (Shianne Chhangur), S.C., J.H., P.S., J.R.K., F.S.R., C.M.D., F.A.A. and M.V.), the UK Biotechnology and Biochemical Sciences Research Council (M.V. and C.M.D.), the Wellcome Trust (M.V. and C.M.D.), Fondi di Ateneo from the University of Florence (F.C.), Darwin College Cambridge (F.S.R.), a Gates Cambridge Scholarship and a St. John's College Benefactors' Scholarship (R.L.), and a Faculty Development Research Fund grant from the United States Military Academy, West Point (R.L.). F.A.A. thanks UK Research and Innovation (Grant MR/S033947/1) and the Alzheimer's Society UK (Grants 317 and 511) for support. P.S. acknowledges the support of a Borysiewicz Biomedical Science Fellowship from the University of Cambridge.

Acknowledgments: The authors thank Ewa Klimont and Swapan Preet for assistance with the expression and purification of the proteins used in this study and Michael Zasloff, MD for kindly providing the molecule trodusquemine.

Conflicts of Interest: The authors declare no conflict of interest. The funders had no role in the design of the study; in the collection, analyses, or interpretation of data; in the writing of the manuscript, or in the decision to publish the results.

\section{Abbreviations}

$\begin{array}{ll}\text { A } \beta & \text { amyloid- } \beta \text { peptide } \\ \text { A } \beta_{40} & \text { 40-residue form of the amyloid- } \beta \text { peptide } \\ \text { A } \beta_{42} & \text { 42-residue form of the amyloid- } \beta \text { peptide } \\ \text { AD } & \text { Alzheimer's disease } \\ \text { AFM } & \text { atomic force microscopy } \\ \text { ANS } & \text { 8-anilinonapthalene-1-sulfonic acid } \\ \text { DesAb } & \text { designed antibody } \\ \text { HFIP } & \text { hexafluoroisopropanol } \\ \text { MTT } & \text { 3-(4,5-dimethylthiazol-2-yl)-2,5-diphenyltetrazolium bromide } \\ \text { SEM } & \text { standard error of the mean } \\ \text { SLS } & \text { static light scattering } \\ \text { ThT } & \text { thioflavin T } \\ \text { TRO } & \text { trodusquemine }\end{array}$

\section{References}

1. Selkoe, D.J.; Hardy, J. The amyloid hypothesis of Alzheimer's disease at 25 years. EMBO Mol. Med. 2016, 8, 595-608. [CrossRef]

2. Knowles, T.P.J.; Vendruscolo, M.; Dobson, C.M. The amyloid state and its association with protein misfolding diseases. Nat. Rev. Mol. Cell Biol. 2014, 15, 384-396. [CrossRef] 
3. Chiti, F.; Dobson, C.M. Protein misfolding, amyloid formation, and human disease: A summary of progress over the last decade. Annu. Rev. Biochem. 2017, 86, 27-68. [CrossRef] [PubMed]

4. Haass, C.; Selkoe, D.J. Soluble protein oligomers in neurodegeneration: Lessons from the Alzheimer's amyloid $\beta$-peptide. Nat. Rev. Mol. Cell Biol. 2007, 8, 101-112. [CrossRef] [PubMed]

5. Benilova, I.; Karran, E.; De Strooper, B. The toxic A $\beta$ oligomer and Alzheimer's disease: An emperor in need of clothes. Nat. Neurosci. 2012, 15, 349-357. [CrossRef]

6. Fontana, I.C.; Zimmer, A.R.; Rocha, A.S.; Gosmann, G.; Souza, D.O.; Lourenco, M.V.; Ferreira, S.T.; Zimmer, E.R. Amyloid- $\beta$ oligomers in cellular models of Alzheimer's disease. J. Neurochem. 2020. [CrossRef] [PubMed]

7. Li, S.; Selkoe, D.J. A mechanistic hypothesis for the impairment of synaptic plasticity by soluble A $\beta$ oligomers from Alzheimer's brain. J. Neurochem. 2020. [CrossRef]

8. Aisen, P.S.; Cummings, J.; Doody, R.; Kramer, L.; Salloway, S.; Selkoe, D.J.; Sims, J.; Sperling, R.A.; Vellas, B. The future of anti-amyloid trials. J. Prev. Alzheimers Dis. 2020, 7, 146-151. [CrossRef] [PubMed]

9. Linse, S.; Scheidt, T.; Bernfur, K.; Vendruscolo, M.; Dobson, C.M.; Cohen, S.I.A.; Sileikis, E.; Lundquist, M.; Qian, F.; O'Malley, T.; et al. Kinetic fingerprints differentiate anti-A $\beta$ therapies. bioRxiv 2020, 815308. [CrossRef]

10. Karran, E.; Hardy, J. A critique of the drug discovery and phase 3 clinical programs targeting the amyloid hypothesis for Alzheimer disease. Ann. Neurol. 2014, 76, 185-205. [CrossRef]

11. Cummings, J.L.; Morstorf, T.; Zhong, K. Alzheimer's disease drug-development pipeline: Few candidates, frequent failures. Alzheimers Res. Ther. 2014, 6, 37. [CrossRef]

12. Holtzman, D.M.; Goate, A.; Kelly, J.; Sperling, R. Mapping the road forward in Alzheimer's disease. Sci. Transl. Med. 2011, 3, 114ps48. [CrossRef]

13. Sperling, R.A.; Jack, C.R.; Aisen, P.S. Testing the right target and the right drug at the right stage. Sci. Transl. Med. 2011, 3, 111cm33. [CrossRef]

14. Aisen, P.S.; Vellas, B.; Hampel, H. Moving towards early clinical trials for amyloid-targeted therapy in Alzheimer's disease. Nat. Rev. Drug Discov. 2013, 12, 324. [CrossRef] [PubMed]

15. Arosio, P.; Vendruscolo, M.; Dobson, C.M.; Knowles, T.P.J. Chemical kinetics for drug discovery to combat protein aggregation diseases. Trends Pharmacol. Sci. 2014, 35, 127-135. [CrossRef] [PubMed]

16. Arosio, P.; Michaels, T.C.T.; Linse, S.; Månsson, C.; Emanuelsson, C.; Presto, J.; Johansson, J.; Vendruscolo, M.; Dobson, C.M.; Knowles, T.P.J. Kinetic analysis reveals the diversity of microscopic mechanisms through which molecular chaperones suppress amyloid formation. Nat. Commun. 2016, 7, 10948. [CrossRef] [PubMed]

17. Meisl, G.; Kirkegaard, J.B.; Arosio, P.; Michaels, T.C.T.; Vendruscolo, M.; Dobson, C.M.; Linse, S.; Knowles, T.P.J. Molecular mechanisms of protein aggregation from global fitting of kinetic models. Nat. Protoc. 2016, 11, 252-272. [CrossRef] [PubMed]

18. Aprile, F.A.; Sormanni, P.; Perni, M.; Arosio, P.; Linse, S.; Knowles, T.P.J.; Dobson, C.M.; Vendruscolo, M. Selective targeting of primary and secondary nucleation pathways in A $\beta 42$ aggregation using a rational antibody scanning method. Sci. Adv. 2017, 3, e1700488. [CrossRef] [PubMed]

19. Habchi, J.; Chia, S.; Limbocker, R.; Mannini, B.; Ahn, M.; Perni, M.; Hansson, O.; Arosio, P.; Kumita, J.R.; Challa, P.K.; et al. Systematic development of small molecules to inhibit specific microscopic steps of A 342 aggregation in Alzheimer's disease. Proc. Natl. Acad. Sci. USA 2016, 201615613. [CrossRef] [PubMed]

20. Chia, S.; Habchi, J.; Michaels, T.C.T.; Cohen, S.I.A.; Linse, S.; Dobson, C.M.; Knowles, T.P.J.; Vendruscolo, M. SAR by kinetics for drug discovery in protein misfolding diseases. Proc. Natl. Acad. Sci. USA 2018, 115, 10245-10250. [CrossRef]

21. Michaels, T.C.T.; Šarić, A.; Curk, S.; Bernfur, K.; Arosio, P.; Meisl, G.; Dear, A.J.; Cohen, S.I.A.; Dobson, C.M.; Vendruscolo, M.; et al. Dynamics of oligomer populations formed during the aggregation of Alzheimer's A 342 peptide. Nat. Chem. 2020, 12, 445-451. [CrossRef] [PubMed]

22. Leader, B.; Baca, Q.J.; Golan, D.E. Protein therapeutics: A summary and pharmacological classification. Nat. Rev. Drug Discov. 2008, 7, 21-39. [CrossRef] [PubMed]

23. Elvin, J.G.; Couston, R.G.; van der Walle, C.F. Therapeutic antibodies: Market considerations, disease targets and bioprocessing. Int. J. Pharm. 2013, 440, 83-98. [CrossRef] [PubMed] 
24. De, S.; Whiten, D.R.; Ruggeri, F.S.; Hughes, C.; Rodrigues, M.; Sideris, D.I.; Taylor, C.G.; Aprile, F.A.; Muyldermans, S.; Knowles, T.P.J.; et al. Soluble aggregates present in cerebrospinal fluid change in size and mechanism of toxicity during Alzheimer's disease progression. Acta Neuropathol. Commun. 2019, 7, 120. [CrossRef] [PubMed]

25. De, S.; Wirthensohn, D.C.; Flagmeier, P.; Hughes, C.; Aprile, F.A.; Ruggeri, F.S.; Whiten, D.R.; Emin, D.; Xia, Z.; Varela, J.A.; et al. Different soluble aggregates of $\mathrm{A} \beta 42$ can give rise to cellular toxicity through different mechanisms. Nat. Commun. 2019, 10, 1541. [CrossRef]

26. Sevigny, J.; Chiao, P.; Bussière, T.; Weinreb, P.H.; Williams, L.; Maier, M.; Dunstan, R.; Salloway, S.; Chen, T.; Ling, Y.; et al. The antibody aducanumab reduces A $\beta$ plaques in Alzheimer's disease. Nature 2016, 537, 50-56. [CrossRef]

27. Aprile, F.A.; Sormanni, P.; Podpolny, M.; Chhangur, S.; Needham, L.-M.; Ruggeri, F.S.; Perni, M.; Limbocker, R.; Heller, G.T.; Sneideris, T.; et al. Rational design of a conformation-specific antibody for the quantification of A $\beta$ oligomers. Proc. Natl. Acad. Sci. USA 2020, 201919464. [CrossRef]

28. Yang, T.; O’Malley, T.T.; Kanmert, D.; Jerecic, J.; Zieske, L.R.; Zetterberg, H.; Hyman, B.T.; Walsh, D.M.; Selkoe, D.J. A highly sensitive novel immunoassay specifically detects low levels of soluble A $\beta$ oligomers in human cerebrospinal fluid. Alzheimers Res. Ther. 2015, 7. [CrossRef]

29. Limbocker, R.; Chia, S.; Ruggeri, F.S.; Perni, M.; Cascella, R.; Heller, G.T.; Meisl, G.; Mannini, B.; Habchi, J.; Michaels, T.C.T.; et al. Trodusquemine enhances A $\beta 42$ aggregation but suppresses its toxicity by displacing oligomers from cell membranes. Nat. Commun. 2019, 10, 225. [CrossRef]

30. Mannini, B.; Mulvihill, E.; Sgromo, C.; Cascella, R.; Khodarahmi, R.; Ramazzotti, M.; Dobson, C.M.; Cecchi, C.; Chiti, F. Toxicity of protein oligomers is rationalized by a function combining size and surface hydrophobicity. ACS Chem. Biol. 2014, 9, 2309-2317. [CrossRef]

31. Ojha, J.; Masilamoni, G.; Dunlap, D.; Udoff, R.A.; Cashikar, A.G. Sequestration of toxic oligomers by HspB1 as a cytoprotective mechanism. Mol. Cell. Biol. 2011, 31, 3146-3157. [CrossRef]

32. Mannini, B.; Chiti, F. Chaperones as suppressors of protein misfolded oligomer toxicity. Front. Mol. Neurosci. 2017, 10. [CrossRef] [PubMed]

33. Mannini, B.; Cascella, R.; Zampagni, M.; van Waarde-Verhagen, M.; Meehan, S.; Roodveldt, C.; Campioni, S.; Boninsegna, M.; Penco, A.; Relini, A.; et al. Molecular mechanisms used by chaperones to reduce the toxicity of aberrant protein oligomers. Proc. Natl. Acad. Sci. USA 2012, 109, 12479-12484. [CrossRef] [PubMed]

34. Campioni, S.; Mannini, B.; Zampagni, M.; Pensalfini, A.; Parrini, C.; Evangelisti, E.; Relini, A.; Stefani, M.; Dobson, C.M.; Cecchi, C.; et al. A causative link between the structure of aberrant protein oligomers and their toxicity. Nat. Chem. Biol. 2010, 6, 140-147. [CrossRef] [PubMed]

35. Cappelli, S.; Penco, A.; Mannini, B.; Cascella, R.; Wilson, M.R.; Ecroyd, H.; Li, X.; Buxbaum, J.N.; Dobson, C.M.; Cecchi, C.; et al. Effect of molecular chaperones on aberrant protein oligomers in vitro: Super-versus sub-stoichiometric chaperone concentrations. Biol. Chem. 2016, 397, 401-415. [CrossRef]

36. Bolognesi, B.; Kumita, J.R.; Barros, T.P.; Esbjorner, E.K.; Luheshi, L.M.; Crowther, D.C.; Wilson, M.R.; Dobson, C.M.; Favrin, G.; Yerbury, J.J. ANS binding reveals common features of cytotoxic amyloid species. ACS Chem. Biol. 2010, 5, 735-740. [CrossRef]

37. Sormanni, P.; Aprile, F.A.; Vendruscolo, M. Rational design of antibodies targeting specific epitopes within intrinsically disordered proteins. Proc. Natl. Acad. Sci. USA 2015, 112, 9902-9907. [CrossRef]

38. Cohen, S.I.A.; Linse, S.; Luheshi, L.M.; Hellstrand, E.; White, D.A.; Rajah, L.; Otzen, D.E.; Vendruscolo, M.; Dobson, C.M.; Knowles, T.P.J. Proliferation of amyloid- $\beta 42$ aggregates occurs through a secondary nucleation mechanism. Proc. Natl. Acad. Sci. USA 2013, 110, 9758-9763. [CrossRef]

39. Sandberg, A.; Luheshi, L.M.; Söllvander, S.; de Barros, T.P.; Macao, B.; Knowles, T.P.J.; Biverstål, H.; Lendel, C.; Ekholm-Petterson, F.; Dubnovitsky, A.; et al. Stabilization of neurotoxic Alzheimer amyloid- $\beta$ oligomers by protein engineering. Proc. Natl. Acad. Sci. USA 2010, 107, 15595-15600. [CrossRef]

40. Bitan, G.; Kirkitadze, M.D.; Lomakin, A.; Vollers, S.S.; Benedek, G.B.; Teplow, D.B. Amyloid $\beta$-protein (A $\beta)$ assembly: A $\beta 40$ and A $\beta 42$ oligomerize through distinct pathways. Proc. Natl. Acad. Sci. USA 2003, 100, 330-335. [CrossRef]

41. Klein, W.L. A $\beta$ toxicity in Alzheimer's disease: Globular oligomers (ADDLs) as new vaccine and drug targets. Neurochem. Int. 2002, 41, 345-352. [CrossRef] 
42. Mannini, B.; Habchi, J.; Chia, S.; Ruggeri, F.S.; Perni, M.; Knowles, T.P.J.; Dobson, C.M.; Vendruscolo, M. Stabilization and characterization of cytotoxic $\mathrm{A} \beta 40$ oligomers isolated from an aggregation reaction in the presence of zinc ions. ACS Chem. Neurosci. 2018, 9, 2959-2971. [CrossRef] [PubMed]

43. Stryer, L. The interaction of a naphthalene dye with apomyoglobin and apohemoglobin: A fluorescent probe of non-polar binding sites. J. Mol. Biol. 1965, 13, 482-495. [CrossRef]

44. Vivoli Vega, M.; Cascella, R.; Chen, S.W.; Fusco, G.; De Simone, A.; Dobson, C.M.; Cecchi, C.; Chiti, F. The toxicity of misfolded protein oligomers is independent of their secondary structure. ACS Chem. Biol. 2019, 14, 1593-1600. [CrossRef]

45. Ruggeri, F.S.; Vieweg, S.; Cendrowska, U.; Longo, G.; Chiki, A.; Lashuel, H.A.; Dietler, G. Nanoscale studies link amyloid maturity with polyglutamine diseases onset. Sci. Rep. 2016, 6, 31155. [CrossRef]

46. Ruggeri, F.S.; Šneideris, T.; Vendruscolo, M.; Knowles, T.P.J. Atomic force microscopy for single molecule characterisation of protein aggregation. Arch. Biochem. Biophys. 2019, 664, 134-148. [CrossRef]

47. Ruggeri, F.S.; Habchi, J.; Cerreta, A.; Dietler, G. AFM-based single molecule techniques: Unraveling the amyloid pathogenic species. Curr. Pharm. Des. 2016, 22, 3950-3970. [CrossRef]

48. Adamcik, J.; Jung, J.-M.; Flakowski, J.; De Los Rios, P.; Dietler, G.; Mezzenga, R. Understanding amyloid aggregation by statistical analysis of atomic force microscopy images. Nat. Nanotechnol. 2010, 5, 423-428. [CrossRef]

49. Ruggeri, F.S.; Charmet, J.; Kartanas, T.; Peter, Q.; Chia, S.; Habchi, J.; Dobson, C.M.; Vendruscolo, M.; Knowles, T.P.J. Microfluidic deposition for resolving single-molecule protein architecture and heterogeneity. Nat. Commun. 2018, 9, 3890. [CrossRef]

50. Ono, K. Alzheimer's disease as oligomeropathy. Neurochem. Int. 2018, 119, 57-70. [CrossRef]

51. Ono, K.; Condron, M.M.; Teplow, D.B. Structure-neurotoxicity relationships of amyloid $\beta$-protein oligomers. Proc. Natl. Acad. Sci. USA 2009, 106, 14745-14750. [CrossRef] [PubMed]

52. Ono, K.; Condron, M.M.; Teplow, D.B. Effects of the English (H6R) and Tottori (D7N) familial Alzheimer disease mutations on amyloid $\beta$-protein assembly and toxicity. J. Biol. Chem. 2010, 285, 23186-23197. [CrossRef] [PubMed]

53. Jin, S.; Kedia, N.; Illes-Toth, E.; Haralampiev, I.; Prisner, S.; Herrmann, A.; Wanker, E.E.; Bieschke, J. Amyloid- $\beta(1-42)$ aggregation initiates its cellular uptake and cytotoxicity. J. Biol. Chem. 2016, 291, 19590-19606. [CrossRef] [PubMed]

54. Dutta, S.; Foley, A.R.; Warner, C.J.A.; Zhang, X.; Rolandi, M.; Abrams, B.; Raskatov, J.A. Suppression of oligomer formation and formation of non-toxic fibrils upon addition of mirror-image $A \beta 42$ to the natural L-enantiomer. Angew. Chem. Int. Ed. 2017, 56, 11506-11510. [CrossRef]

55. Dutta, S.; Finn, T.S.; Kuhn, A.J.; Abrams, B.; Raskatov, J.A. Chirality dependence of amyloid $\beta$ cellular uptake and a new mechanistic perspective. ChemBioChem 2019, 20, 1023-1026. [CrossRef]

56. Perni, M.; Galvagnion, C.; Maltsev, A.; Meisl, G.; Müller, M.B.D.; Challa, P.K.; Kirkegaard, J.B.; Flagmeier, P.; Cohen, S.I.A.; Cascella, R.; et al. A natural product inhibits the initiation of $\alpha$-synuclein aggregation and suppresses its toxicity. Proc. Natl. Acad. Sci. USA 2017, 114, E1009-E1017. [CrossRef]

57. Perni, M.; Flagmeier, P.; Limbocker, R.; Cascella, R.; Aprile, F.A.; Galvagnion, C.; Heller, G.T.; Meisl, G.; Chen, S.W.; Kumita, J.R.; et al. Multistep inhibition of $\alpha$-synuclein aggregation and toxicity in vitro and in vivo by trodusquemine. ACS Chem. Biol. 2018, 13, 2308-2319. [CrossRef]

58. Zhang, X.; Rao, M.N.; Jones, S.R.; Shao, B.; Feibush, P.; McGuigan, M.; Tzodikov, N.; Feibush, B.; Sharkansky, I.; Snyder, B.; et al. Synthesis of Squalamine utilizing a readily accessible Spermidine equivalent. J. Org. Chem. 1998, 63, 8599-8603. [CrossRef]

59. Rao, M.; Shinnar, A.; Noecker, L.; Chao, T.; Feibush, B.; Snyder, B.; Sharkansky, I.; Sarkahian, A.; Zhang, X.; Jones, S.; et al. Aminosterols from the Dogfish Shark Squalus acanthias. J. Nat. Prod. 2000, 63, 631-635. [CrossRef]

60. Habchi, J.; Arosio, P.; Perni, M.; Costa, A.R.; Yagi-Utsumi, M.; Joshi, P.; Chia, S.; Cohen, S.I.A.; Müller, M.B.D.; Linse, S.; et al. An anticancer drug suppresses the primary nucleation reaction that initiates the production of the toxic A $\beta 42$ aggregates linked with Alzheimer's disease. Sci. Adv. 2016, 2, e1501244. [CrossRef]

61. Ruggeri, F.S.; Adamcik, J.; Jeong, J.S.; Lashuel, H.A.; Mezzenga, R.; Dietler, G. Influence of the $\beta$-sheet content on the mechanical properties of aggregates during amyloid fibrillization. Angew. Chem. Int. Ed. 2015, 54, 2462-2466. [CrossRef] 
62. Capitini, C.; Conti, S.; Perni, M.; Guidi, F.; Cascella, R.; De Poli, A.; Penco, A.; Relini, A.; Cecchi, C.; Chiti, F. TDP-43 inclusion bodies formed in bacteria are structurally amorphous, non-amyloid and inherently toxic to neuroblastoma cells. PLoS ONE 2014, 9, e86720. [CrossRef] [PubMed]

63. Evangelisti, E.; Cascella, R.; Becatti, M.; Marrazza, G.; Dobson, C.M.; Chiti, F.; Stefani, M.; Cecchi, C. Binding affinity of amyloid oligomers to cellular membranes is a generic indicator of cellular dysfunction in protein misfolding diseases. Sci. Rep. 2016, 6, 32721. [CrossRef] [PubMed]

64. Evangelisti, E.; Cecchi, C.; Cascella, R.; Sgromo, C.; Becatti, M.; Dobson, C.M.; Chiti, F.; Stefani, M. Membrane lipid composition and its physicochemical properties define cell vulnerability to aberrant protein oligomers. J. Cell Sci. 2012, 125, 2416-2427. [CrossRef] [PubMed]

(C) 2020 by the authors. Licensee MDPI, Basel, Switzerland. This article is an open access article distributed under the terms and conditions of the Creative Commons Attribution (CC BY) license (http://creativecommons.org/licenses/by/4.0/). 